\title{
INFLUENCE OF MODIFICATION OF CARBON NANOTUBES ON THE MICROSTRUCTURE AND PERCOLATION BEHAVIOR OF THE SYSTEMS BASED ON POLYETHYLENE GLYCOL
}

\author{
E. A. Lysenkov ${ }^{1}$, V. V. Klepko ${ }^{2}$, I. P. Lysenkova ${ }^{1}$ \\ ${ }^{1}$ Mykolayiv V. O. Sukhomlynskiy National University \\ 24, Nikol'ska St., Mykolayiv, UA-54030, Ukraine \\ ${ }^{2}$ Institute of Macromolecular Chemistry of NAS of Ukraine, \\ 48, Kharkiv Hwy, Kyiv, UA-02160, Ukraine \\ (Received June 06, 2017; in final form - December 20, 2017)
}

\begin{abstract}
Research into the microstructure, electric and dielectric properties of the systems based on polyethylene glycol and multiwalled carbon nanotubes (MWCNTs), which were functionalized by different methods is done using the methods of impedance spectroscopy and optical microscopy. It is determined that the probed systems show the percolation behavior. It is discovered that when using of OH-functionalized MWCNTs, the percolation threshold of conductivity is increased from $0.44 \%$ to $0.55 \%$, and using $\mathrm{H}_{2} \mathrm{O}$-functionalized MWCNTs, the percolation threshold of conductivity is increased to $3 \%$. It is determined that the percolation threshold of dielectric permittivity considerably increases when functionalized MWCNTs are used.
\end{abstract}

Key words: nanocomposites, percolation behavior, carbon nanotubes, conductivity, functionalization of nanotubes.

PACS number(s): 73.61.Ph, 73.63.Fg

\section{INTRODUCTION}

Polymer nanocomposites filled with carbon nanotubes (CNTs) have been attracting the considerable attention of researchers already for over 20 years. This interest is determined mostly by the unique properties of CNTs that allow to use nanocomposites filled with CNTs in many areas: from electronics to materials science $[1,2]$. Thus, due to good functional descriptions of CNTs, nanocomposites filled with them have exceptional mechanical, electric, thermophysical, optical characteristics, even when CNTs content in the polymeric matrix is low $[3,4]$.

However, properties of polymer nanocomposite material filled by CNTs considerably depend on the type of CNTs (single-walled or multiwalled), physical and chemical state of their surface and methods of polymer and nanofiller mixing $[5,6]$. In case of direct mixing of CNTs in a liquid polymeric matrix it is very hard to divide bundles and aggregates of CNTs and to get the random distribution of the nanofiller. Aggregation of CNTs causes decreasing of the interphase area in nanocomposites, wich results in worsening of their functional descriptions. So, the key requirement for the realization of the desired improvement of functional descriptions of nanocomposites is achieving a homogeneous dispersion of CNT in a polymeric matrix.

Chemical modification of CNTs surface forming covalently bonded special functional groups are applied for the improvement of CNTs dispersion when creating different nanocomposite materials [7]. As shown in works $[8,9]$, the chemical type of functionalization considerably improves the distribution of CNTs in a polymeric matrix, which plays a critical role in the forming of both ther- mal and electric properties of polymeric nanocomposites. This type of modification also leads to an increase in contacts between CNTs, which is crucial to the creation of a percolation network and creates more possibilities of covalent bonding of the nanotube to the matrix due to the functional groups on their surface. On the other hand, surface functionalization with the use of strong oxidants can destroy the structure of CNTs, which leads to a reduction of the amount of nanotubes and creation of defects in the graphene structure of their walls $[10,11]$.

In work [12] the authors applied the soft type of modification (physical functionalization) with the use of different anionic, cationic and non-ionogenic surfactants for the exfoliation of CNTs bunches on individual nanotubes in different solvents. In such systems, modification of CNTs surface with low-molecular compounds takes place due to non-covalent supramolecular interactions, in particular hydrophobic-hydrophobic interaction, van der Waals forces, $\pi-\pi$ interaction, formation of hydrogen bonding and electrostatic attraction [13]. This approach eliminates the necessity of previous treatment of CNTs with strong oxidants for functionalization of their surface. It allows to improve interaction and dispersion of nanotubes in most solvents with the maintainance of their mechanical, electric and optical descriptions. Consequently, research into the influence of CNTs functionalization on the microstructure and properties of polymeric nanocomposites is a relevant task and a promising direction in the creation of new nanocomposites materials. Therefore, the purpose of this work is to study the influence of CNTs functionalization on a microstructure, percolation behavior, electric and dielectric properties of the model polymer/CNTs system based on polyethylene glycol. 


\section{EXPERIMENTAL PART}

\section{A. Materials}

Polyethylene glycol (PEG-400) HO[- $\left.\mathrm{CH}_{2}-\mathrm{CH}_{2}-\mathrm{O}-\right]_{n} \mathrm{H}$ $(n=9)$ with the molecular mass of $M_{w}=400$ (Aldrich) was used as a fluidic polymer matrix. Its density at $T=$ $293 \mathrm{~K}$ was $\rho=1013 \mathrm{~kg} / \mathrm{m}^{3}$. PEG-400 is an oily viscous liquid. Before using, PPG-400 was dewatered by heating in vacuum $(2 \mathrm{~mm})$ at residual pressure $p=270 \mathrm{~Pa}$ and temperature $T=363-383 \mathrm{~K}$ during 5 hours.

Multi-walled CNTs (MWCNTs) of three types of functionalization were used as a filler. Non-functionalized MWCNTs (TNM3) ("Timesnano", Chengdu Organic Chemicals Co. Ltd., China) are produced by natural gas catalytic decomposition over Ni-based catalyst. MWCNTs-OH (TNMH3) are hydroxyl-functionalized TNM3. They are produced by $\mathrm{KMnO}_{4}$ oxidation in $\mathrm{H}_{2} \mathrm{SO}_{4}$ solution at different temperatures and $\mathrm{KMnO}_{4}$ concentrations. The content of hydroxyl groups was $3.06 \%$. MWCNTs- $\mathrm{H}_{2} \mathrm{O}$ are water-functionalized MWCNTs (493A) ("Specmash" Ltd., Ukraine) and are made by the method of CVD (chemical vapour deposition) with FeAlMo as a catalyst. The content of sorbed water was $7 \%$.

The typical outer diameter $d$ of all the MWCNTs used for the preparation of the systems was 30-50 nm [14], their length $l$ was $5-10 \mu \mathrm{m}$ and mean aspect ratio was $a=l / d=100-300$. The specific surface area of the powders determined by $\mathrm{N}_{2}$ adsorption was $S>100 \mathrm{~m}^{2} / \mathrm{g}$. The purity of MWCNTs was $>98$ wt. \%. The electrical conductivity, $\sigma$, of MWCNTs was about $10 \mathrm{~S} / \mathrm{cm}$.

\section{B. Preparation of composite materials}

The composites were obtained by adding the appropriate weights of the filler (MWCNTs) to PPG-400 at $T=323 \mathrm{~K}$ (viscosity is $30 \mathrm{mPa} \cdot \mathrm{s}$ ) with subsequent 5 min sonication of the mixture using a UZDN-2T ultrasonic disperser at the frequency of $22 \mathrm{kHz}$ and the output power of $150 \mathrm{~W}$. A series of samples with the content of MWCNTs within 0.1-10 wt. \% was investigated.

\section{Testing and characterization}

Electric properties of nanocomposites are investigated by the method of impedance spectroscopy realized on the basis of impedancemeter Z-2000 (Russia). A sample is placed between the electrodes of a cell and the real $\left(Z^{\prime}\right)$ and imaginary $\left(Z^{\prime \prime}\right)$ parts of impedance are measured. From the frequency dependence of complex impedance the direct current (DC) conductivity $\sigma=d / R S$ is determined using the method described in [15]. Here, $S$ is the area and $d$ is the thickness of the sample, respesctively. The measurements are carried out at the room temperature in the frequency range $1 \mathrm{~Hz}-2 \mathrm{MHz}$.

The transmittance microphotographs of the nanocomposites are received using the optical XY-B2 microscope
(China), equipped with the ICM 532 digital video eyepiece and with the AMCAP/VIDCAP (Microsoft) system of image treatment. The probed samples are placed in a glass cell with the thickness of $100 \mu \mathrm{m}$.

\section{RESULTS AND DISCUSSION}

\section{A. Microstructure of the PEG-MWCNTs systems}

The microscopic images of the investigated nanocomposites based on PEG are presented on Fig. 1. As we can see from the micrographs, fractal aggregates appear in the probed systems filled with MWCNTs of different types. Comparing with MWCNTs, in the case of introduction of MWCNTs-OH, the aggregates appear more fluffed, which is explained by the attraction forces between the $\mathrm{OH}$-functionalized nanotubes. But, in the case of introduction of MWCNTs- $\mathrm{H}_{2} \mathrm{O}$, the aggregates appear more dense and compact. It is shown that, when the concentration of MWCNTs (Fig. 1,a) and MWCNTs-OH (Fig. 1,b) is $0.2 \%$ and the concentration of MWCNTs$\mathrm{H}_{2} \mathrm{O}$ (Fig. 1,c) is $0.5 \%$, single clusters which do not contact between themselves appear. When the MWCNTs content is $0.5 \%$, the formation of a percolation cluster in the system based on PEG (connection of single aggregates forms a continuous structure) is observed (Fig. $1, \mathrm{~d})$. However in the system filled with MWCNTs-OH and MWCNTs- $\mathrm{H}_{2} \mathrm{O}$, a continuous cluster does not appear during at this concentration. The formation of a percolation cluster in the system filled with MWCNTs$\mathrm{OH}$ and $\mathrm{MWCNTs}-\mathrm{H}_{2} \mathrm{O}$ is observed when the filler content is $0.75 \%$ (Fig. 1,h) and 3\% (Fig. 1,i), respectively.

From the microscopic images it is possible to estimate the fractal dimension $\left(d_{\mathrm{f}}\right)$, which represents the morphology of the clusters of MWCNTs in the 2D projection. The images were analysed using the box-counting method, with the help of the image analysis software ImageJ v1.41. The 'capacity' fractal dimension was obtained from the dependence of the number of boxes necessary to cover the boundary of an aggregate $N$ versus the box size $L[16]$ :

$$
N \propto L^{d_{\mathrm{f}}}
$$

For the estimation of fractal dimension all images were translated into a binary format. The dependence of the fractal dimension on the MWCNTs content in the system is presented on Fig. 2. The unmonotonous growth of $d_{\mathrm{f}}$ with the increase in the number of MWCNTs in the system is observed on Fig. 2. Such behavior was also observed for different types of systems filled with MWCNTs, for example, for PEG-1000-MWCNTs [17] and for binary liquid mixtures water-1-Cyclohexyl-2pyrrolidone-MWCNTs [18]. The value of $d_{\mathrm{f}}$ lies in the range from 1 (the case of linear aggregates) to 2 (the case of dense aggregates). As we can see from Fig. 2, the behavior of the fractal dimension for the investigated systems filled with nanotubes of different types differs 
considerably. When the content of nanotubes is $0.2 \%, d_{\mathrm{f}}$ of the system filled with MWCNTs-OH is higher than for the system filled with unmodified MWCNTs. It indicates a better distribution of the modified nanotubes in a polymeric matrix due to the attraction between separate CNTs. However, such attraction leads to an increase in the percolation threshold comparing to using unmodified MWCNTs. Thus, the percolation threshold for the PEG-MWCNTs system is $0.5 \%$, and for the PEG-
MWCNTs-OH system it lies in the range from $0.6 \%$ to $0.7 \%$. Unmodified MWCNTs, due to powerful van der Waals attraction forces, form denser aggregates, that is why a continuous cluster appears at lower concentrations comparing to MWCNTs-OH. Consequently, OHfunctionalization of MWCNTs results in a more random distribution of nanotubes in a polymeric matrix, however it leads to an increase in the value of the percolation threshold.

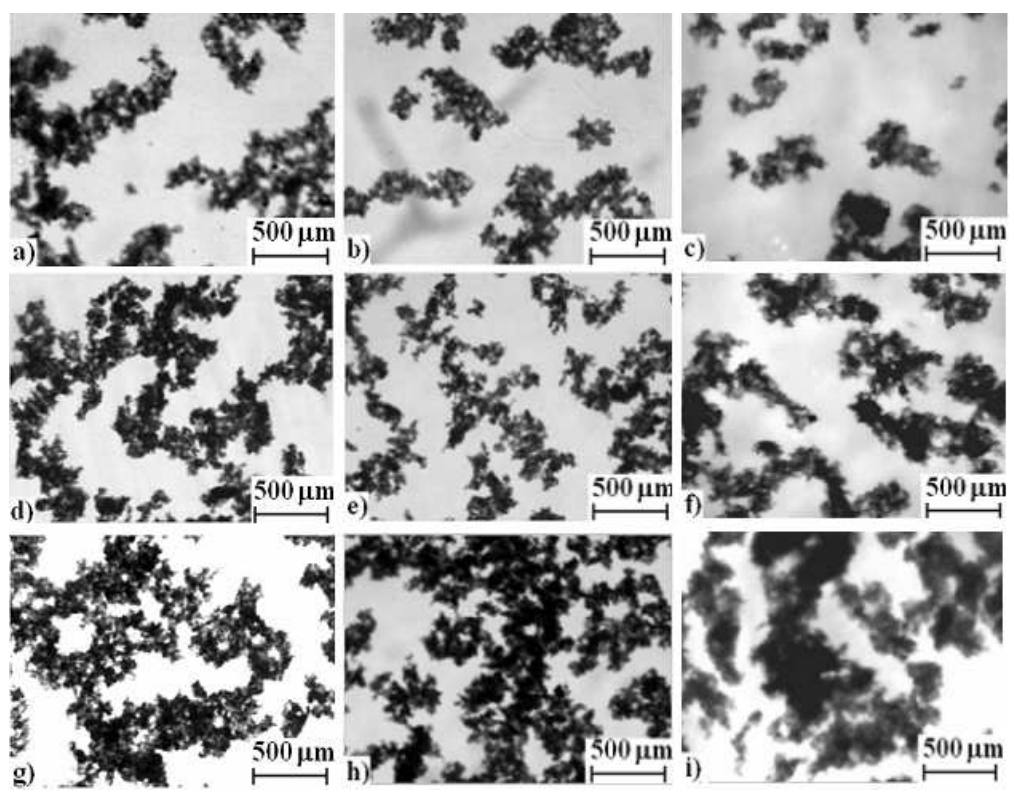

Fig. 1. The microscopic images of the nanocomposites based on PEG filled with MWCNTs (a, d, g), MWCNTs-OH (b, e, h) and MWCNTs- $\mathrm{H}_{2} \mathrm{O}(\mathrm{c}, \mathrm{f}, \mathrm{i})$. MWCNTs and MWCNTs-OH content was $0.2 \%(\mathrm{a}, \mathrm{b}), 0.5 \%(\mathrm{~d}, \mathrm{e}), 0.75 \%(\mathrm{~g}, \mathrm{~h}), \mathrm{MWCNTs}^{-} \mathrm{H}_{2} \mathrm{O}$ content was $0.5 \%$ (c), $1 \%$ (f), $3 \%$ (i).

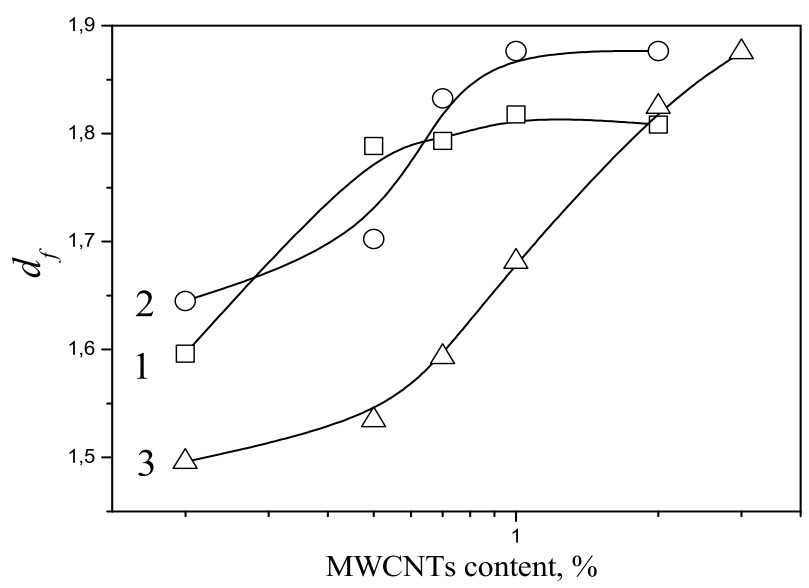

Fig. 2. Dependence of the fractal dimension on the filler content for the system based on PEG filled with unmodified MWCNTs (1), MWCNTs-OH (2) and MWCNTs- $\mathrm{H}_{2} \mathrm{O}$ (3).

Unlike the microstructure of PEG-MWCNTs and PEG-MWCNTs-OH systems, large and very dense aggregates form in the system filled with $\mathrm{MWCNTs} \mathrm{H}_{2} \mathrm{O}$ (Fig. 1,c,f,i). The formation of large dense aggregates leads to the lower fractal dimention (Fig. 2, curve 3) and to an increases in the percolation threshold. The percolation threshold for the PEG-MWCNTs- $\mathrm{H}_{2} \mathrm{O}$ system is near $3 \%$.

\section{B. Percolation behavior of the conductivity}

The structural organization of the modified MWCNTs introduced in the polymer nanocomposite determines physical properties of the system. The dependences of conductivity on the nanofiller content for the investigated systems based on PEG filled with MWCNTs, MWCNTs-OH and MWCNTs- $\mathrm{H}_{2} \mathrm{O}$ are represented on Fig. 3. The step-like change of the conductivity is associated with the percolation phenomenon and is observed in different intervals for the systems filled with different nanotubes. For the systems filled with MWCNTs and MWCNTs-OH this range is $0.4-1.5 \%$, for the systems filled with MWCNTs- $\mathrm{H}_{2} \mathrm{O}$ this range is $3-10 \%$. After the percolation threshold, is achieved the conductivity of all systems is almost an order higher than its values below the percolation threshold.

According to the percolation theory, the relation between the electric conductivity and the content of a conducting nanofiller in systems is described by the scaling 
law [19, 20]:

$$
\sigma \propto\left(p-p_{c}\right)^{t},
$$

where $p$ is the mass fraction of a conducting nanofiller, $p_{c}$ the critical mass fraction of a nanofiller at the percolation transition (the percolation threshold), and the power exponent $t$ is the critical exponent of conductivity. The exponent $t$ mainly depends on the dimension of the system and does not depend on the structure of the particles that form clusters as well as on the interaction between them.

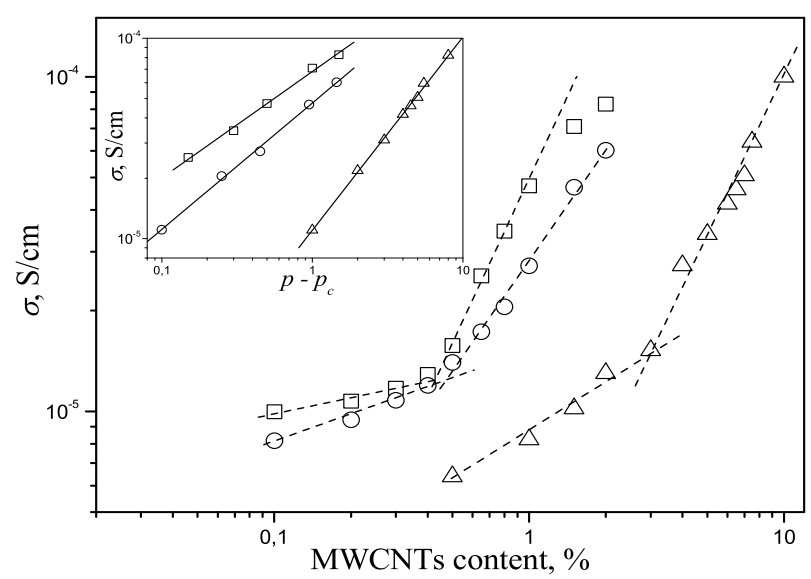

Fig. 3. The dependences of the conductivity on CNTs content for the systems based on PEG-400 filled with MWCNTs (squares), MWCNTs-OH (circles) and MWCNTs- $\mathrm{H}_{2} \mathrm{O}$ (triangles). The dependences of the conductivity in the coordinates of Eq. (2) are shown in the inset.

\begin{tabular}{|c|c|c|c|c|}
\hline Name/formalism & \multicolumn{2}{|c|}{$\sigma(p)$} & \multicolumn{2}{c|}{$\varepsilon(p)$} \\
\hline Samples & $p_{c}, \%$ & $t$ & $p_{c}, \%$ & $q$ \\
\hline PEG-MWCNTs & 0.50 & $1.20 \pm 0.08$ & 0.55 & $0.55 \pm 0.05$ \\
\hline PEG-MWCNTs-OH & 0.55 & $1.34 \pm 0.07$ & 0.8 & $0.72 \pm 0.04$ \\
\hline PEG-MWCNTs- $\mathrm{H}_{2} \mathrm{O}$ & 3.0 & $1.47 \pm 0.08$ & 3.5 & $0.69 \pm 0.07$ \\
\hline
\end{tabular}

Table 1. Percolation parameters for the systems based on PEG, filled be MWCNTs, MWCNTs-OH and MWCNTs$\mathrm{H}_{2} \mathrm{O}$.

By applying the least-squares method and Eq. (2) for the description of experimental data (Fig. 3), we determined the percolation threshold $p_{c}$ and the critical exponent $t$. The results of the approximation for the systems filled with nanotubes with different types of modification are shown in Table 1. The values of the percolation thresholds correlate well with the information microscopic images (Fig. 1), which specify the formation of the continuous cluster in the PEG-MWCNTs system when the nanofiller content is $<0.5 \%$, and in the PEG-MWCNTs$\mathrm{OH}$ system when the value of the nanofiller content lies in the interval from $0.5 \%$ to $0.75 \%$. The rapid increase of the percolation threshold to $3 \%$ is observed for the system filled with $\mathrm{H}_{2} \mathrm{O}$-functionalized MWCNTs. As we can see from the values of the percolation threshold cited in Table 1, the percolation conducting cluster for the systems which contain unfunctionalized MWCNTs appears at lower concentrations than for the systems which contain functionalized MWCNTs. It should be noted that the use of modified and unmodified MWCNTs for the creation of nanocomposites based on PEG-400 does not influence the general level of conductivity of the system, which in all cases has the value near $10^{-4} \mathrm{~S} / \mathrm{cm}$.

The value of the critical exponents for the systems based on PEG increases with the use of nanotubes in such order MWCNTs $\rightarrow$ MWCNTs-OH $\rightarrow$ MWCNTs- $\mathrm{H}_{2} \mathrm{O}$. The increase of the value of $t$ meens the increase of the structural dimension of the clusters and a more random distribution of functionalized MWCNTs in a polymeric matrix [21].

The differences in the values of the percolation thresholds and the critical indexes for the systems filled with different types of nanotubes can be explained as follows. The conductivity of nanofilled polymeric composites is due to the existence of two mechanisms of charges transfer: the motion of electrons through continuous percolation clusters from MWCNTs, which form direct contacts between themselves, and the hopping mechanism which is realized by default for direct contacts between the particles of the filler [22-24].

At the MWCNTs concentration lower than the percolation threshold (formation of the continuous cluster), the basic mechanism of conductivity is a hopping mechanism, i.e., the jumping of charges from one nanotube to another; that is why the conductivity is inverse proportionally dependent on the distance between MWCNTs. At the MWCNTs concentration higher than the percolation threshold, when the nanotubes form direct contacts, the value of conductivity depends on the amount of conducting clusters and the amount of free charge carriers in MWCNTs. The functionalization of MWCNTs results in the decrease in the amount of free electrons in the nanotube through their chemical interaction with hydroxyl groups.

The interaction of oligomeric chains with the modified surface is improved due to the presence of hydroxyl groups on the nanotube surface. This effect leads to appearance of the layer of adsorbed molecules, which destroy electric contacts and increase the distance between MWCNTs in clusters. Besides, the breaking of the chemical structure of the nanotubes at the covalent modification considerably worsens their own conductivity. The considerable increas in the percolation threshold observed when MWCNTs- $\mathrm{H}_{2} \mathrm{O}$ are used is explained by the fact that the molecules of water on the surface of the nanotube not only destroy the direct contacts between MWCNTs but also remove them on a distance, which an electron cannot overcome by either the hopping mechanism or the tunneling mechanism. So, the modification of the nanotubes leads to a better distribution of MWCNTs and destroys their aggregates, but decreases the conductivity of the systems filled with functionalized fillers. 


\section{Percolation behavior of the dielectric permittivity}

The dielectric permittivity is one of the key parameters of composition materials, which determines their functional descriptions and makes it possible to apply such systems as a basis for the creation of condensers of variable capacity. According to literary data, for the nanofilled conducting systems there is a sharp jump of the dielectric permittivity in the area of percolation transition $[25,26]$.

The dependences of the dielectric permittivity on MWCNTs content for the systems based on polyethylene glycol are shown on Fig. 4. The rapid increase of the dielectric permittivity is associated with the percolation phenomenon and is observed in different intervals for the systems, filled by different nanotubes. For the systems filled with MWCNTs and MWCNTs$\mathrm{OH}$ this range is $0.7-1.5 \%$, for the systems filled with MWCNTs- $\mathrm{H}_{2} \mathrm{O}$ this range is $2-10 \%$. After the percolation threshold is reached the dielectric permittivity increases in 14, 6 and 26 times for the systems filled with MWCNTs, MWCNTs-OH and MWCNTs- $\mathrm{H}_{2} \mathrm{O}$, respectively. The phenomenon of the sharp increase of the dielectric permittivity in the area of percolation transition is confirmed by the literature [25-27]. In [27] it was shown that the dielectric permittivity for the system based on polyethylene increases in 66 times, comparing to the neat polymeric matrix after introduction of the critical concentration of iron particles.

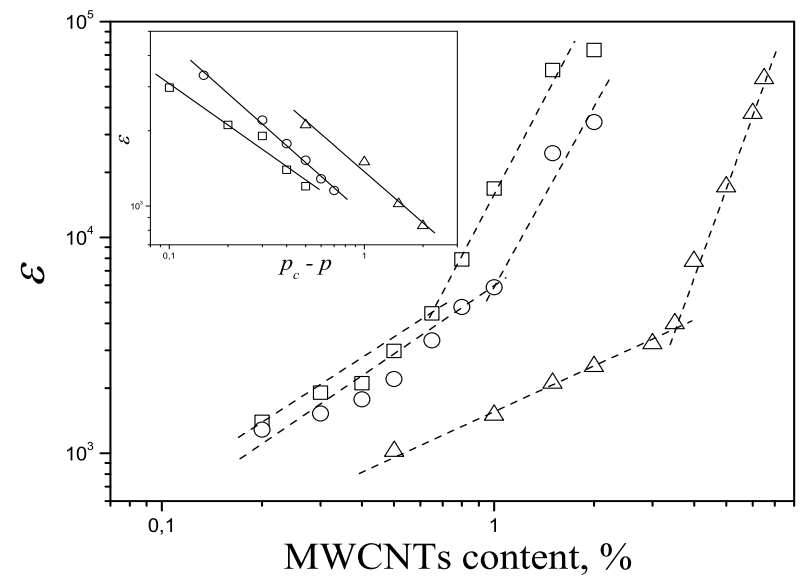

Fig. 4. The dependences of the dielectric permittivity on MWCNTs content for the systems based on PEG-400 filled with MWCNTs (squares), MWCNTs-OH (circles) and MWCNTs- $\mathrm{H}_{2} \mathrm{O}$ (triangles) at frequency of $1 \mathrm{kHz}$. The dependences of the dielectric permittivity in the coordinates of Eq. (3)are shown in the inset.

In the percolation systems, nanofillers form conducting clusters and when the percolation threshold is reached these clusters unite in the conducting channels which pass through all volume of the system. Each two of the conducting channels are electrodes of condenser and are characterized by large capacity. The conducting channels are connected in parallel. As is known, the resulting capacity of the parallely connected condensers is equal to the sum of the capacities of all of the condensers. That is why the dielectric permittivity of the systems increases sharply when the percolation threshold is reached [28].

The difference in the increase in the dielectric permittivity for the systems filled with different nanotubes can be explained as follows. For the PEG-MWCNTs system, results in the formation of a branched structure of the percolation cluster. In this case, the cluster has a large surface area, and MWCNTs form direct contacts between themselves. It is known that the capacity of a condenser is proportional to the surface area of the contact with the insulator and inverse proportional to the distance between the electrodes. Due to the presence of functional OH-groups on the surface of MWCNTs, the distance between the nanotubes in the clusters increases. That leads to a decrease of the general capacity of the investigated systems. Therefore, the dielectric permittivity of the PEG-MWCNTs systems, after the percolation threshold, is higher than the dielectric permittivity of the PEG-MWCNTs-OH systems.

According to the percolation theory, the relation between the dielectric permittivity and the content of a conducting nanofiller in systems is described by the scaling law [26]:

$$
\varepsilon \propto\left(p-p_{c}\right)^{-q},
$$

where $\varepsilon$ is the dielectric permittivity of the nanofilled system, $p$ is the mass fraction of the conducting nanofiller, $p_{c}$ the critical mass fraction of the nanofiller at the percolation transition (the percolation threshold), and the power exponent $q$ is the critical exponent of the dielectric permittivity.

By applying the least-squares method and Eq. (3) for the description of the experimental data (Fig. 4), we determined the percolation threshold $p_{c}$ and the critical exponent $q$. The results of approximation for the systems filled with nanotubes with different types of modification are shown in Table 1 . These values correlate with the values of the percolation thresholds received from the analysis of the conductivity data. However, the values of $p_{c}$ determined from the analysis of the dielectric permittivity are higher than the values of $p_{c}$ determined from the analysis of the conductivity. As we can see from Table 1 , the values of the critical exponent $q$ for nanocomposite systems filled with functionalized MWCNTs are very close to the theoretical values $q=0.73[21]$. In the percolation theory, the quantity $q$ is coupled with the dimensions of the electric channels consisting of clustercomposing MWCNTs. According to the results of works $[21,29]$, the value of the exponent $q$ characterizes the average number of MWCNTs in the clusters. For conductive percolation clusters with an identical effective volume to be formed, a smaller number of MWCNTs, in comparison with functionalized MWCNTs, which do not always form direct contacts between themselves, should be taken. That is why the value of $q$ for the the systems PEG-MWCNTs is smaller than that for systems containing functionalized MWCNTs. 


\title{
E. A. LYSENKOV, V. V. KLEPKO, I. P. LYSENKOVA
}

\section{CONCLUSIONS}

The influence of nanofiller functionalization on the structure and properties of the systems based on polyethylene glycol and multiwalled carbon nanotubes (MWCNTs) was studied as a result of the conducted research. It is established that the investigated systems show a percolation behavior. It is discovered that the use of functionalized MWCNTs leads to the increase in the percolation threshold of the nanocomposite systems from $0.5 \%$ (in the case of unmodified MWCNTs) to $3 \%$. This happens due to the obstacles created by hydroxyl groups and molecules of water on the surface of a nanotube, which results in the decrease of the conductivity. It is shown that the value of the percolation thresholds is confirmed by microscopic images. It is established that the dielectric permittivity of the investigated systems also shows a percolation behavior and depends on MWCNTs functionalization. It is shown that in the case of introduction of $\mathrm{OH}$-functionalized and $\mathrm{H}_{2} \mathrm{O}$ functionalized MWCNTs, the percolation thresholds are $0.8 \%$ and $3.5 \%$ respectively, while for unfunctionalized MWCNTs, the percolation threshold is $0.5 \%$. Such behavior is explained by the increase of the distance between the modified nanotubes.
[1] Z. Spitalsky, D. Tasis, D. Papagelis, S. Galiotis, Progr. Polym. Sci. 35, 357 (2010).

[2] E. A. Lysenkov, O. V. Stryutskiy, Yu. P. Gomza, V. V. Klepko, Funct. Mater. 22, 40 (2015).

[3] M. M. J. Treacy, T. W. Ebbesen, J. M. Gibson, Nature 381, 678 (1996).

[4] R. V. Dinzhos, N. M. Fialko, E. A. Lysenkov, J. NanoElectron. Phys. 6, 01015 (2014).

[5] V. V. Klepko, E. A. Lysenkov, Ukr. J. Phys. 60, 944 (2015).

[6] E. A. Lysenkov, V. V. Klepko, Yu. V. Yakovlev, J. NanoElectron. Phys. 7, 01031 (2015).

[7] S. Banerjee, T. Hemraj-Benny, S. S. Wong, Adv. Mater. 17, 17 (2005).

[8] Q. Li, L. Dong, L. Li, S X. u, H. Xie, C. Xiong, Carbon 50, 2056 (2012).

[9] K. Madhukar et al., Polym. Eng. Sci. 53, 394 (2012).

[10] M. Monthioux, B. W. Smith, B. Burteaux, A. Claye, J. E. Fischer, D. E. Luzzi, Carbon 39, 1251 (2001).

[11] M. S. Strano et al., Science 301, 1519 (2003).

[12] A. J. Blanch, C. E. Lenehan, J. S. Quinton, J. Polym. Sci. Polym. Lett. B 114, 9805 (2010).

[13] T. Premkumar, R. Mezzenga, K. E. Geckeler, Small 8, 1299 (2012).

[14] E. Lysenkov, I. Melnyk, L. Bulavin, V. Klepko, N. Lebovka, in Physics of Liquid Matter: Modern Problems, Springer Proceedings in Physics (Springer International Publishing, Switzerland, 2015), p. 165.
[15] A. Kyritsis, P. Pissis, J. Grammatikakis, J. Polymer. Sci. B 33, 1737 (1995).

[16] J. Feder, Fractals (Springer Science \& Business Media, 2013).

[17] N. I. Lebovka et al., J. Compos. Mater. 45, 2555 (2011).

[18] O. Deriabina, N. Lebovka, L. Bulavin, A. Goncharuk, Physica E 59, 150 (2014).

[19] S. Kirkpatrick, Phys. Rev. Lett. 27, 1722 (1971).

[20] I. Webman, J. Jortner, M. H. Cohen, Phys. Rev. B 16, 2593 (1977).

[21] D. Stauffer, A. Aharony, Introduction to Percolation Theory (Taylor and Francis Group, London, 1994).

[22] W. Bauhofer, J. Z. Kovacs, Compos. Sci. Technol. 69, 1486 (2009).

[23] M. J. Jiang, Z. M. Dang, H. P. Xu, Appl. Phys. Lett. 90, 42914 (2007).

[24] E. A. Lysenkov, V. V. Klepko, J. Nano- Electron. Phys. 5, 03052 (2013).

[25] L. Wang, Z.-M. Dang, Appl. Phys. Lett. 87, 042903 (2005).

[26] Y. J. Li, M. Xu, J. Q. Feng, Z.-M. Dang, Appl. Phys. Lett. 89, 072902 (2006).

[27] I. Chodak, I. Krupa, J. Mater. Sci. Lett. 18, 1457 (1999).

[28] D. J. Bergman, Y. Imry, Phys. Rev. Lett. 39, 1222 (1977).

[29] Y. Gefen, A. Aharony, S. Alexander, Phys. Rev. Lett. 50, 77 (1983).

\section{ВПЛИВ МОДИФІКАЦЇ̈ ВУГЛЕЦЕВИХ НАНОТРУБОК НА МІКРОСТРУКТУРУ ТА ПЕРКОЛЯЦЙНУ ПОВЕДІНКУ СИСТЕМ НА ОСНОВІ ПОЛІЕТИЛЕНГЛІКОЛЮ}

\author{
Е. А. Лисенков, В. В. Клепко ${ }^{2}$, І. П. Лисенкова ${ }^{1}$ \\ ${ }^{1}$ Миколаӥвсъкий начіоналъний університет ім. В. О. Сухомлинсъкого, \\ вул. Нікольсъка, 24, Миколаїв, 54030, Україна \\ ${ }^{2}$ Інститут хімї̈ високомолекулярних сполук НАН Украӥни, \\ Харківсъке шосе, 48, Київ, 02160, Украӥна
}

\begin{abstract}
Використовуючи методи імпедансної спектроскопії та оптичної мікроскопії, проведено дослідження мікроструктури, електричних та діелектричних властивостей систем на основі поліетиленгліколю та вуглецевих нанотрубок, функціоналізованих різними методами. Встановлено, що досліджувані системи проявляють перколяційну поведінку. Виявлено, що при використанні нанотрубок, функціоналізованих гідроксильними групами, поріг електричної перколяції збільшується з $0.44 \%$ до $0.55 \%$, а використовуючи нанотрубки, функціоналізовані водою, поріг електричної перколяції збільшується до 3\%. Встановлено, що поріг перколяції для діелектричної проникності значно зростає при використанні функціоналізованих нанотрубок.
\end{abstract}

